\title{
REDUÇÃO NO NÚMERO DE PLACAS DE REFRIGERAÇÃO QUEIMADAS NO ALTO FORNO 2 DA CSN*
}

\author{
Marco Polo da Silva Peixoto ${ }^{1}$ \\ Marcio José Mariano da Silva ${ }^{2}$ \\ Jose de Moraes Pereira ${ }^{3}$ \\ Sandro Batista Junior ${ }^{4}$
}

\section{Resumo}

O presente trabalho tem por objetivo apresentar a redução do número de queima de placas de refrigeração no Alto Forno 2 da C.S.N, onde são destacadas as principais ações operacionais implementadas para obtenção dos resultados até a presente data e a redução de perdas no custo e elevação da produtividade.

Palavras-chave: Redução de queima de placas de refrigeração; Ações operacionais; Alto forno 2; Redução de perdas no custo.

\section{REDUCTION OF THE NUMBER OF COOLING PLATES BURNED IN BLAST FURNACE 2 OF CSN}

\begin{abstract}
This paper aim to present the reduction of the number of burning cooling plates in Blast Furnace 2 of the CSN, where the main operational actions implemented for attainment of the results until the present date and the reduction of losses in the cost and increase of productivity are detached.
\end{abstract}

Keywords: Operational reduction of burning cooling plates; Actions; Blast Furnace 2; Reduction of losses in the cost.

\footnotetext{
Engenheiro de Processo de Alto Forno, Gerência de Altos-Fornos, CSN, Volta Redonda, RJ, Brasil. Engenheiro Especialista de Alto Forno, Gerência de Altos-Fornos, CSN, Volta Redonda, RJ, Brasil. 3 Técnico de desenvolvimento de Alto Forno, Gerência de Altos-Fornos, CSN, Volta Redonda, RJ, Brasil.

4 Técnico Especialista de Alto Forno, Gerência de Altos-Fornos, CSN, Volta Redonda, RJ, Brasil.
} 


\section{INTRODUÇÃO}

O alto forno 2 deu início a sua $5^{a}$ campanha em 23/02/1991 e operou até 20/11/2000, produzindo pouco mais de 14 milhões de toneladas de gusa, quando foi realizado uma troca de todo o refratamento do corpo e parte do cadinho com objetivo de prolongar sua campanha até 2009. Após pouco mais de 8 anos, com uma produção acumulada de 11,97 milhões de toneladas, e aproveitando a baixa demanda de aço no mercado mundial, uma nova mini reforma foi realizada em 29/03/2009 mantendo o mesmo escopo da mini reforma realizada no ano de 2000.

Nessa mini reforma do equipamento foi trocado todo refratamento do corpo utilizando tijolos de grafite na rampa, ventre e baixa cuba, na média cuba foram utilizados tijolos de carbeto de silício e na alta cuba refratários silico-aluminos e alta alumina, conforme Figura 2. Na região do cadinho foi feita a reconstituição da parede, acerca de $120^{\circ}$ entre e além dos furos de gusa, é o serviço de maior responsabilidade para garantir a previsão de mais 8 anos de operação ao alto forno, conforme Figura 1.

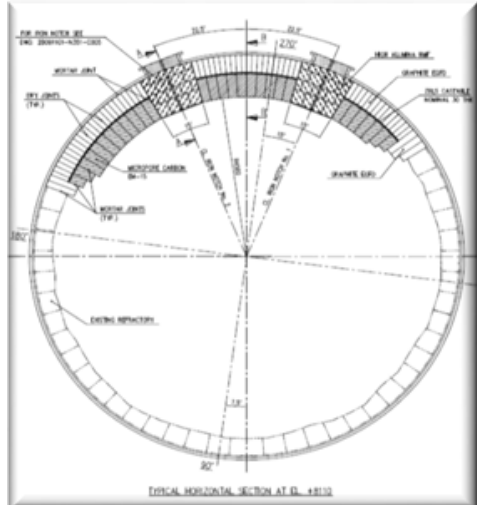

Figura 1: Refratamento do cadinho entre os furos de gusa

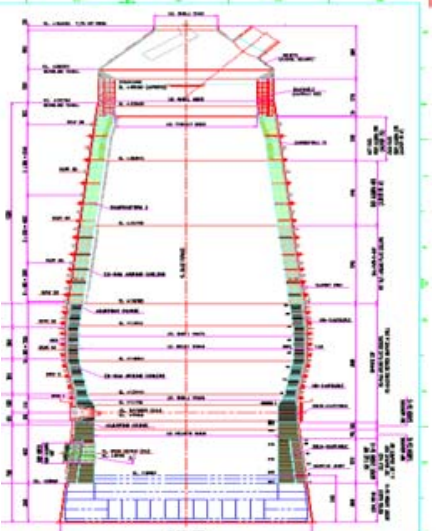

Figura 2:Refratamento do corpo do forno 2 da C.S.N

Com a elevação das exportações brasileiras de minério de ferro e o aumento do preço do minério de ferro mercado chinês, a C.S.N. também iniciou sua participação nesse mercado atrativo a partir de 2010, conforme Figura 3.

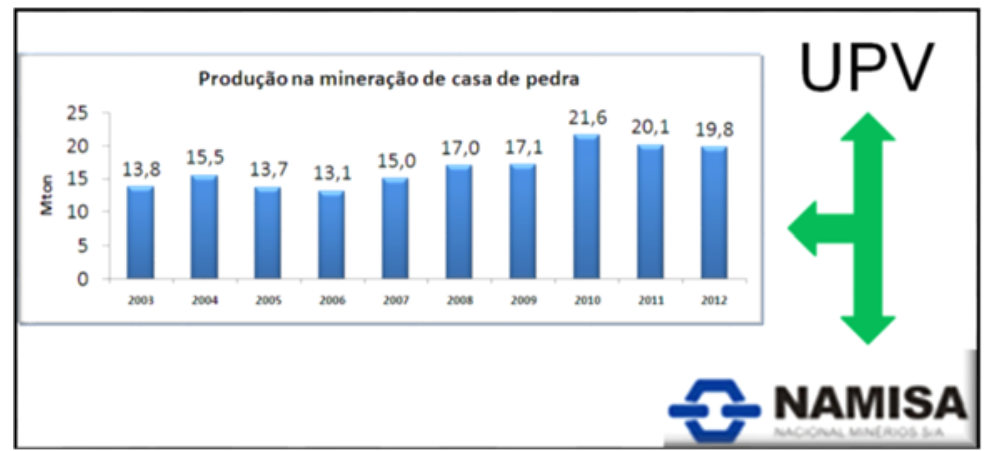

Figura 3: Produção da mineração de Casa de Pedra.

Visando prolongar a vida útil da mina de Casa de Pedra e aumentar a produção de minério para exportação foi necessário elevar a participação de minérios de ferro de alto teor de ganga na composição do blend. Essas alterações são evidenciadas pela evolução dos teores de Sílica no sinter feed e HAF. 


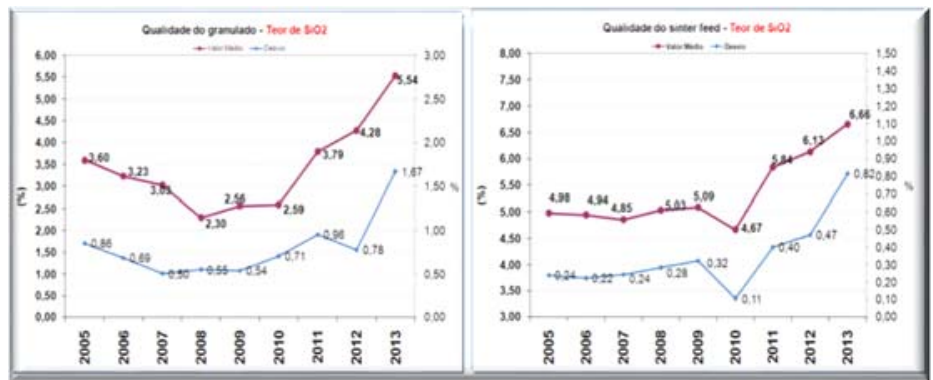

Figura 4 - Qualidade do minério granulado e sinter feed

Como efeito dessa elevação de sílica nos minérios de Casa de Pedra, o slag rate dos altos fornos da C.S.N. se elevaram conforme Figura 5.

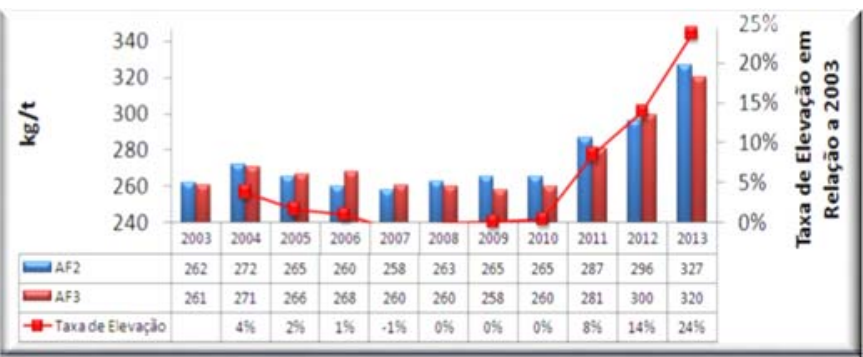

Figura 5 - Volume de escória dos altos fornos

Paralelo a isso, a produção de coque próprio da C.S.N em 2013. Reduziu fortemente, tendo assim a necessidade de se completar o mix de coque dos altos fornos, com coque externo.

Esse cenário forçou então a um novo modelo operacional do Alto Forno 2 da C.S.N, o qual foi a solução para vários efeitos colaterais, como o da Figura 6 , que será o motivo do trabalho em questão: Redução no número de placas de refrigeração queimadas no alto forno 2 da C.S.N.

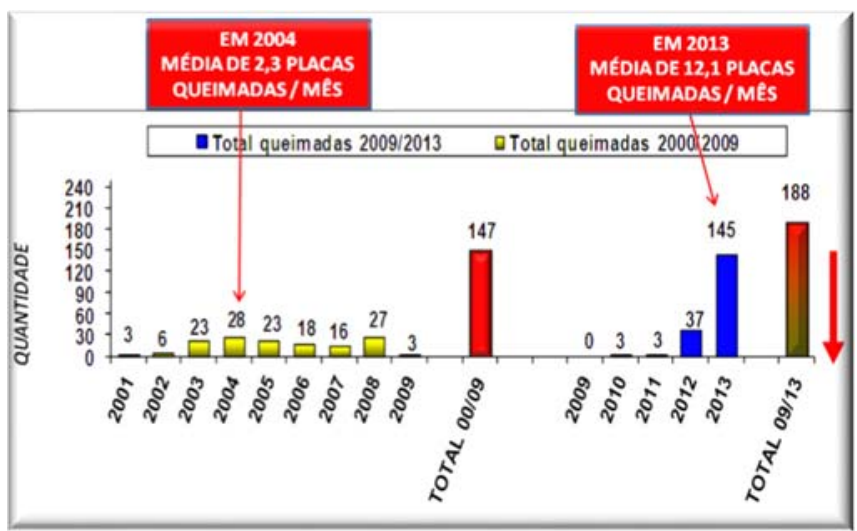

Figura 6- Comparativo do $\mathrm{N}^{\circ}$ de placas de refrigeração queimadas no AF\#2.

\section{MATERIAIS E MÉTODOS}

Para a realização desse trabalho foi estabelecido que o MSP (metodologia de soluções de problemas) seria a melhor ferramenta a ser aplicada, iniciando com o levantamento das perdas, seguindo com a observação no local para a determinação das causas e proposição de ações para minimizar as perdas causadas pelo problema. Com o aumento de incidência de entrada de água e das marchas irregulares no alto forno 2 da C.S.N, devido à elevação do $\mathrm{N}^{\circ}$ de placas de refrigeração queimadas, 
apareceu então como reflexo direto desse problema as perdas no fuel rate e produtividade, como mostramos a seguir:

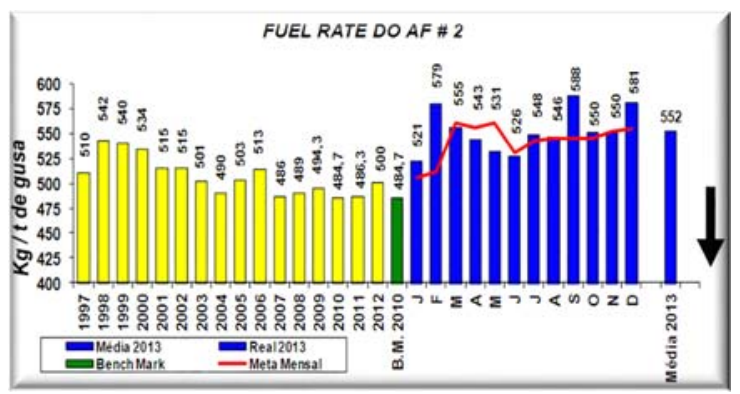

Figura 7- Elevação do fuel rate no AF\#2 em 2013.

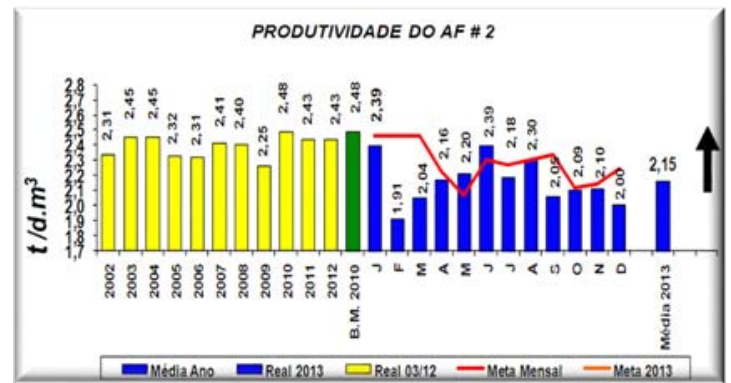

Figura 8- Redução da produtividade no AF\#2 em 2013.

A configuração das placas de refrigeração no alto forno 2 da C.SN. segue o mapa planificado na Figura 9.

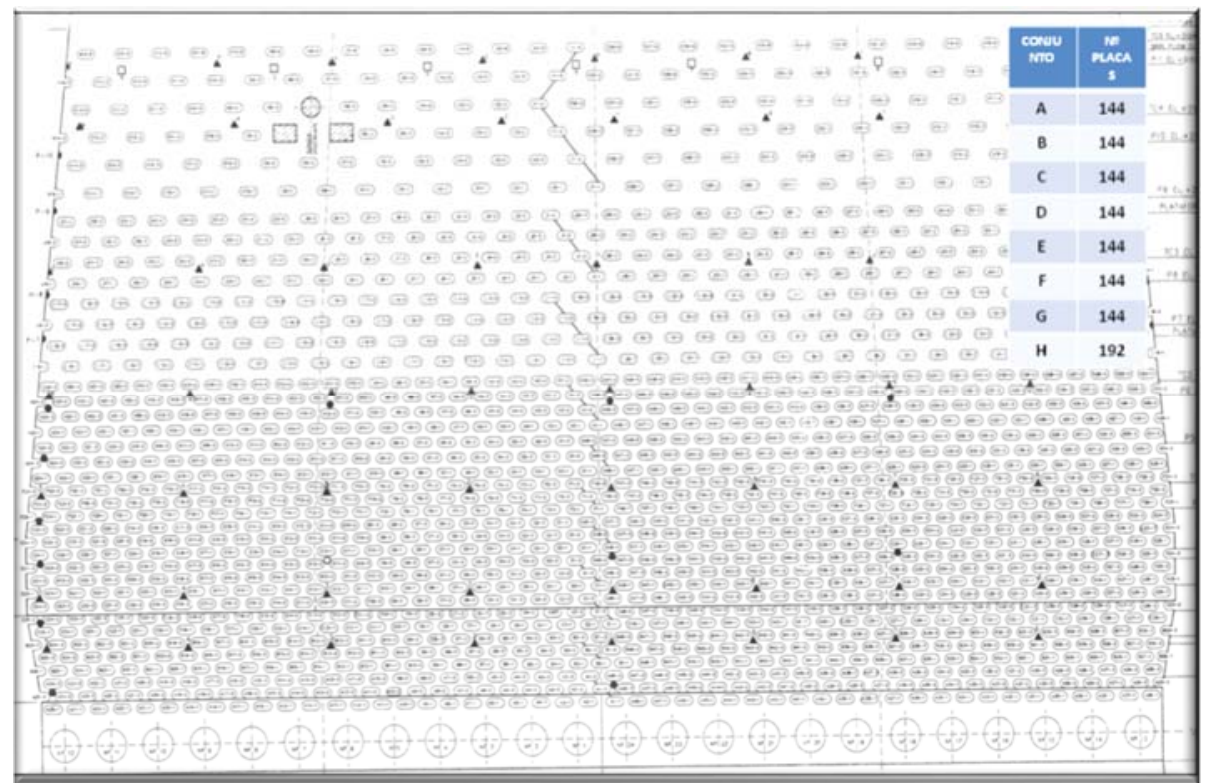

Figura 9- Desenho planificado do corpo do AF\#2 mostrando as placas de refrigeração

O total é de 1653 placas de refrigeração dispostas em filas classificadas por conjuntos e obedecendo a ordem alfabética da rampa até a alta cuba (conforme tabela abaixo), Verificamos que a incidência de queima, se acentua na região de produção de líquidos e que do total de placas queimadas, 94\% fica nessa região, conforme Figura 10. 


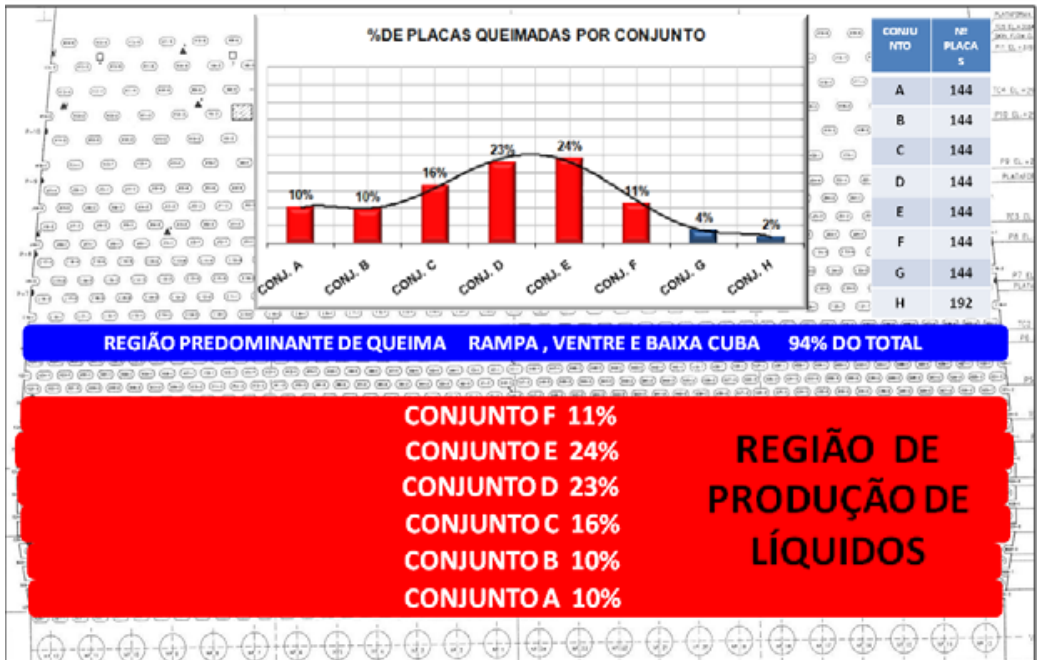

Figura 10- Região de maior incidência de queima (rampa, ventre e baixa cuba).

Observamos também, que com o desgaste natural dos refratários da parede, as placas ficavam com sua extremidade expostas dentro do forno e que $100 \%$ das placas queimavam em sua extremidade (Figura 11).

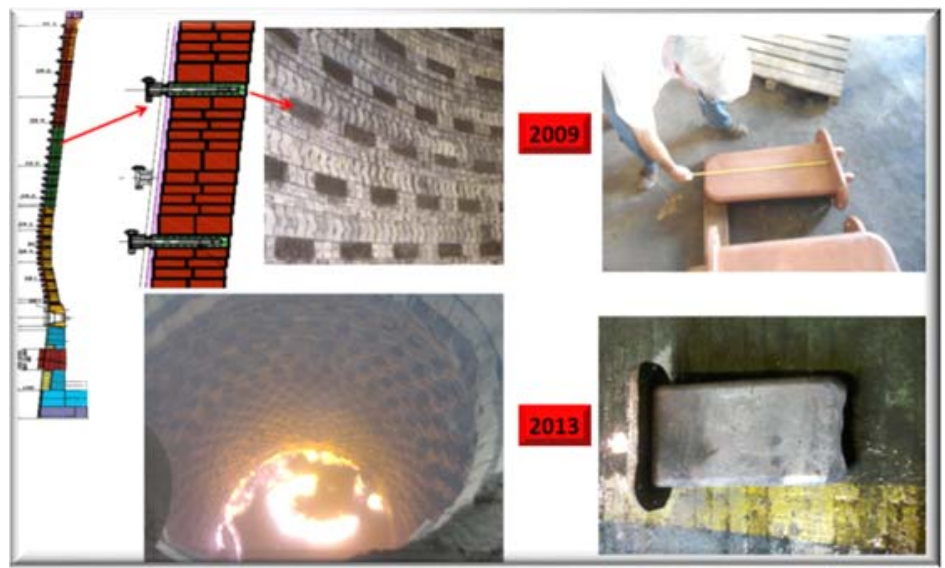

Figura $11-100 \%$ das placas queimam em sua extremidade

Outra observação importante foi o fato que das 1653 placas, trocamos 550 placas na mini reforma de 2009 e que os percentuais de placas antigas queimadas e o de placas novas, foram quase proporcionais aos percentuais de placas antigas que não foram trocadas e o de placas novas que entraram em 2009 (Figura 12).

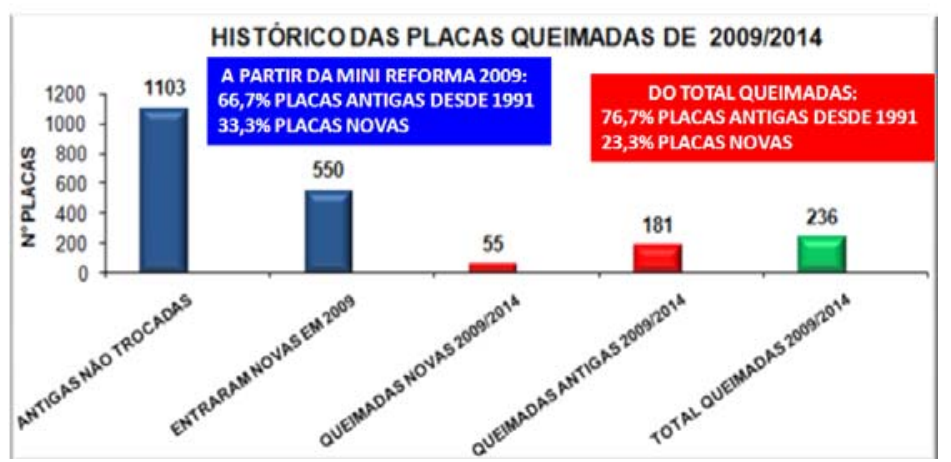

Figura 12- Relação de placas queimadas novas e antigas, com as placas que ficaram desde 1991 até 2009 e placas que entraram novas em 2009. 
Outro fato importante foi que verificamos que quando o alto forno 2 entrava em regime de marcha operacional irregular, queimava-se um número elevado de placas e quando esse fato, não acontecia, não se queimava placas no AF\#2.

Na figura 13 mostramos os gráficos do desvio padrão do ar soprado em alguns meses no AF\#2, onde é verificado a influência da marcha operacional irregular na queima de placas de refrigeração. Quanto maior o desvio padrão do ar soprado, maior a instabilidade operacional do AF\#2 e consequentemente maior o número de placas de refrigeração queimadas (Figuras 13 e 14).

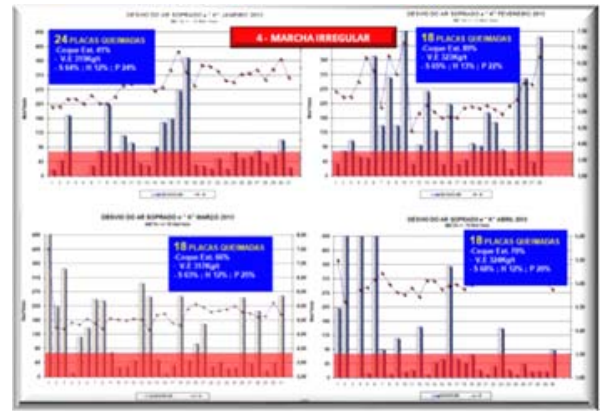

Figura 13- Relação de placas queimadas com a instabilidade operacional do AF\#2 meses de JANEIRO à ABRIL de 2013

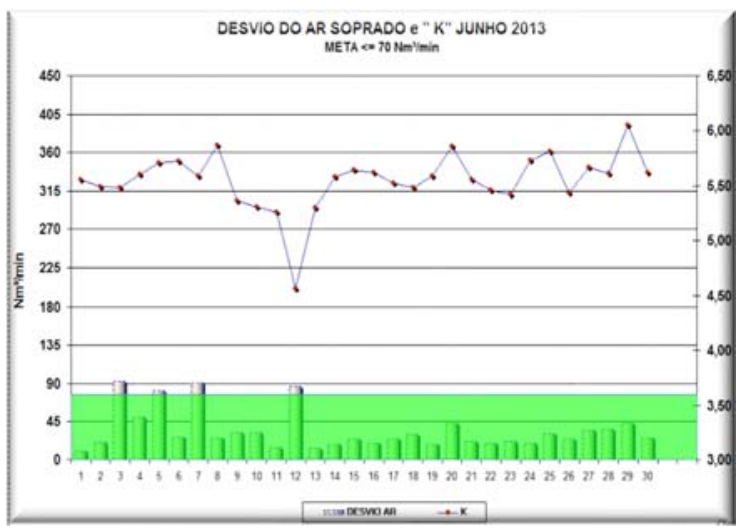

Figura 14- Relação entre marcha operacional estável e nenhuma placa queimada no AF\#2

Após brainstorming, a equipe chegou a conclusão das seguintes hipóteses, correlacionando os seguintes fatos (Figura 15).

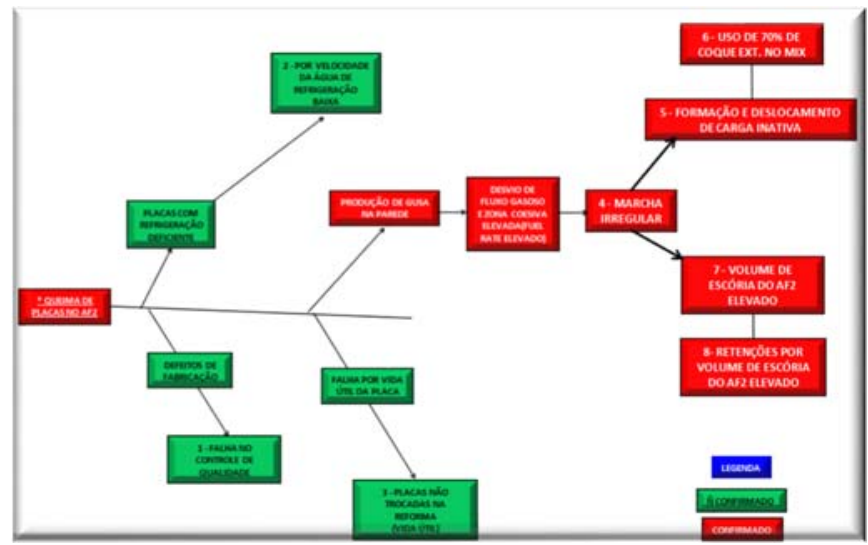

Figura 15 - Diagrama de Relação X Teste de Hipótese. 
As causas relacionadas, apontaram para a produção de gusa na parede (extremidade da placa) devido à marcha irregular por:

- Formação de carga inativa na parede (cascão);

- Uso de 70\% de coque externo no mix de coque do AF\#2;

- Volume de escória (slag rate) elevado no AF\#2;

- Retenções de escória por slag rate elevado;

- Distribuição de carga X Tempo de descarga dos materiais na correia.

Já que as possíveis causas como, Falha no controle de qualidade, Placas com refrigeração deficiente, Vida útil, não foram comprovadas.

De posse das causas mais prováveis, partimos para o plano de ação (Figura 16).

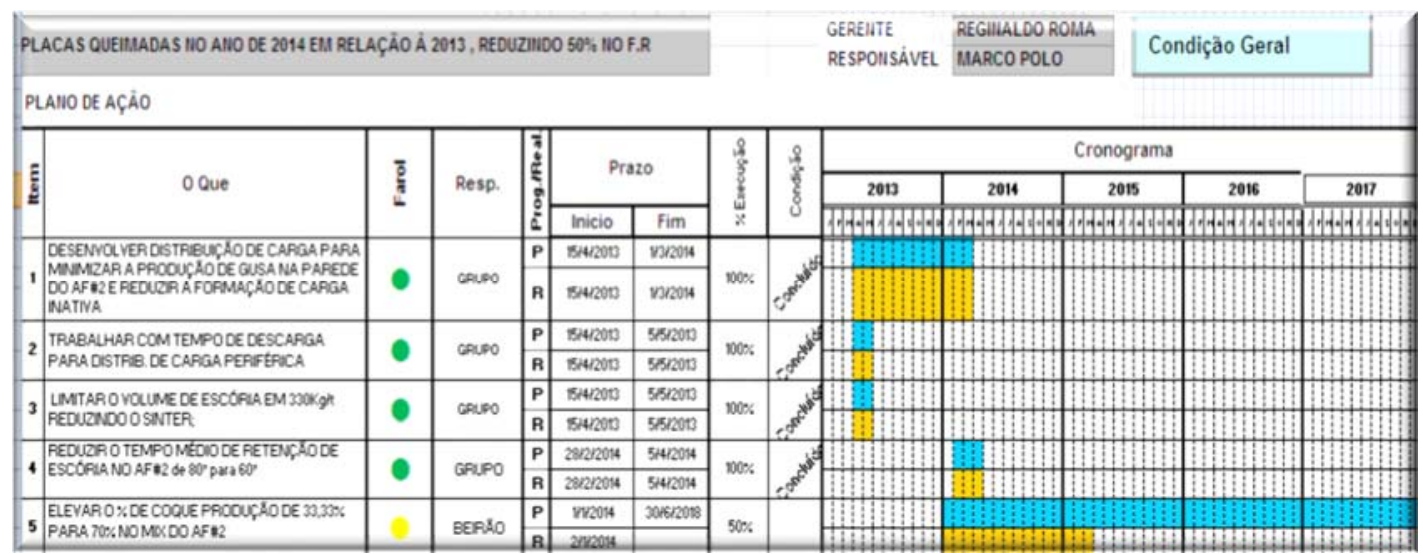

Figura 16 - Cronograma das ações efetuadas

\subsection{Ação 1 - Desenvolver Distribuição de Carga para Minimizar a Produção de Gusa na Parede do Af\#2 E Reduzir a Formação de Carga Inativa}

Comentário: Atualmente trabalhamos com 4 distribuição de cargas diferentes, conforme Figura 17, objetivando um percentual maior de coque na parede e no período de agosto até outubro de 2014 (Figura 18), nós conseguimos obter êxito no controle da formação de carga inativa (cascão).

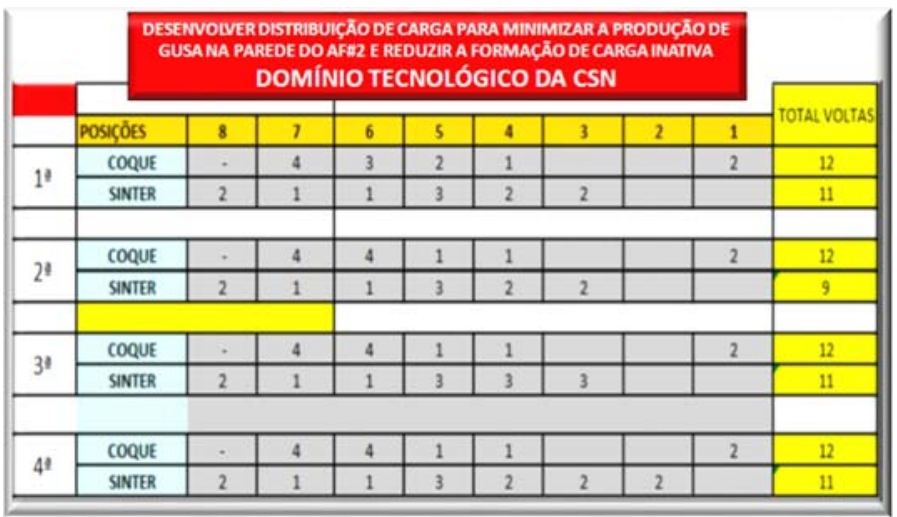

Figura 17 - Distribuição de carga do AF\#2 


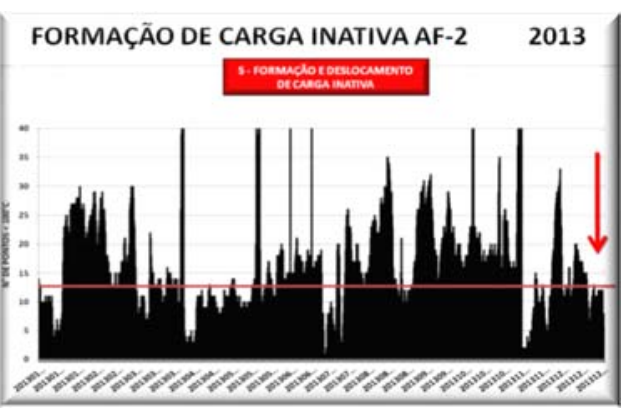

Figura 18 - Período Antes e depois da nova distribuição de carga

\subsection{Ação 2 - Trabalhar com Tempo de Descarga para Distribuição de Carga Periférica}

Comentário: Com as novas distribuições de carga, tivemos que utilizar mais o recurso do tempo de descarga na correia principal, potencializando tanto a proteção da parede contra a produção de gusa próximo as placas de refrigeração, quanto a remoção de carga inativa (cascão).

\begin{tabular}{|c|c|c|c|}
\hline \multicolumn{4}{|c|}{$\begin{array}{l}\text { TRABALHAR COM TEMPO DE DESCARGA PARA DISTRIB. } \\
\text { CARGA PERIFERICA }\end{array}$} \\
\hline \multirow{2}{*}{\multicolumn{2}{|c|}{ BALANÇA }} & \multicolumn{2}{|c|}{ TEMPO DESCARGA } \\
\hline & & ANTES & DEPOIS \\
\hline 30 & SINTER & 45 & 10 \\
\hline 40 & SINTER & 45 & 10 \\
\hline 50 & SINTER & 50 & 10 \\
\hline 61 & HEMATITA & 50 & 60 \\
\hline 62 & PELOTA & 0 & 50 \\
\hline 71 & CASCALHO & 70 & 60 \\
\hline 72 & PELOTA & & 65 \\
\hline 81 & SMALL COQUE & 0 & 0 \\
\hline 82 & PELOTA & & 50 \\
\hline
\end{tabular}

Figura 19 - Período Antes e depois da nova distribuição de carga

\subsection{Ação 3 - Limitar o Volume de Escória em $330 \mathrm{~kg} / \mathrm{T}$ Reduzindo o Sinter}

Comentário: Essa ação visou controlar o volume de escória, favorecendo o escoamento do $\mathrm{AF} \# 2$, reduzindo assim marcha irregular por desvio de fluxo gasoso, já que sabemos que o mal escoamento do forno, afeta fortemente a permeabilidade dos altos fornos, e consequentemente afeta toda fluidodinâmica do mesmo.

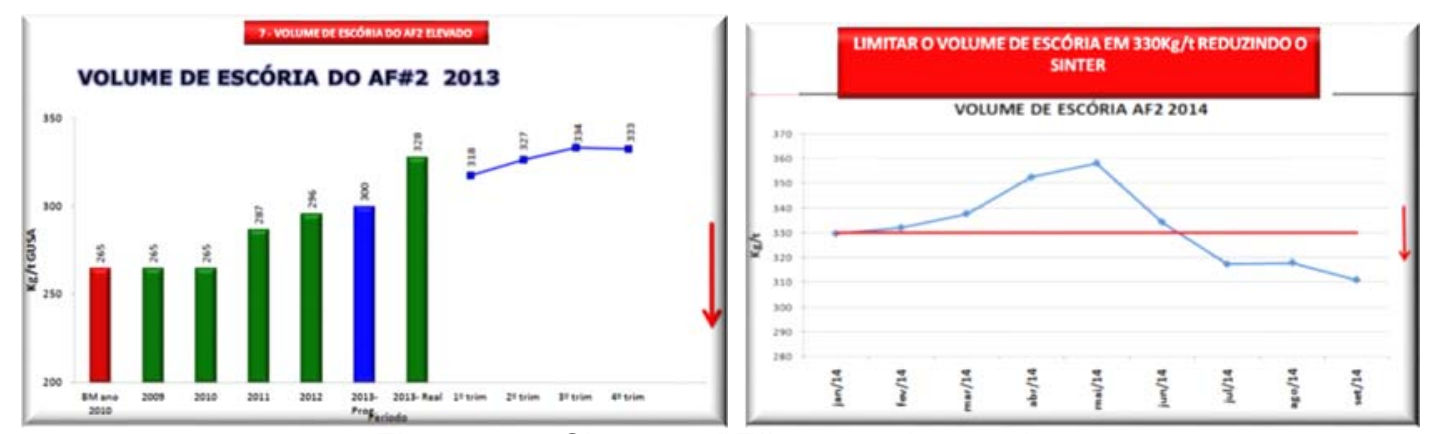

Figura 20 - Slag rate AF\#2 em 2013 e 2014 


\subsection{Ação 4 - Reduzir o Tempo Médio de Retenção de Escória no Af\#2 de 80' para 60 '}

Comentário: Essa ação, aliada a ação de redução do slag rate do AF\#2, promove um escoamento dos líquidos do forno mais eficaz e consequentemente reduz as irregularidades na fluidodinâmica do mesmo. Na figura 21 podemos observar a melhora do índice de acerto de retenção de escória no ano de 2014, comparado com 2013.
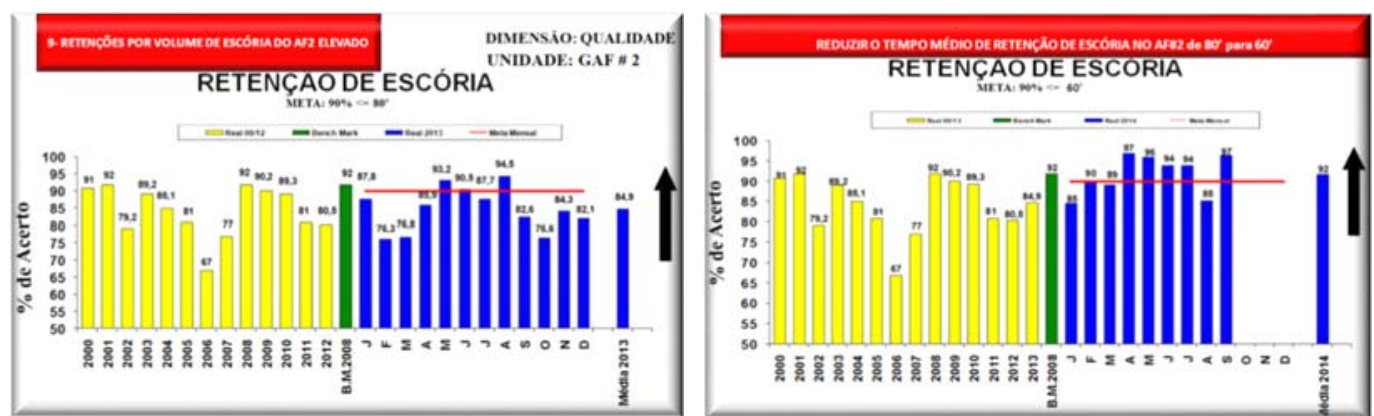

Figura 21 - Índice de acerto de retenção de escória em 2013 e 2014.

\subsection{Ação 5 - Elevar a \% de Coque Produção de 33,33\% para 70\% no Mix do Af\#2}

Comentário: Com a recuperação de parte da produtividade da coqueria. Reduzimos a participação de coque externo no mix do AF\#2 de $70 \%$ para $50 \%$. Essa ação contribui fortemente, para que o tamanho médio do coque enfornado seja maior proporcionando uma melhora significativa na permeabilidade e marcha operacional do AF\#2.

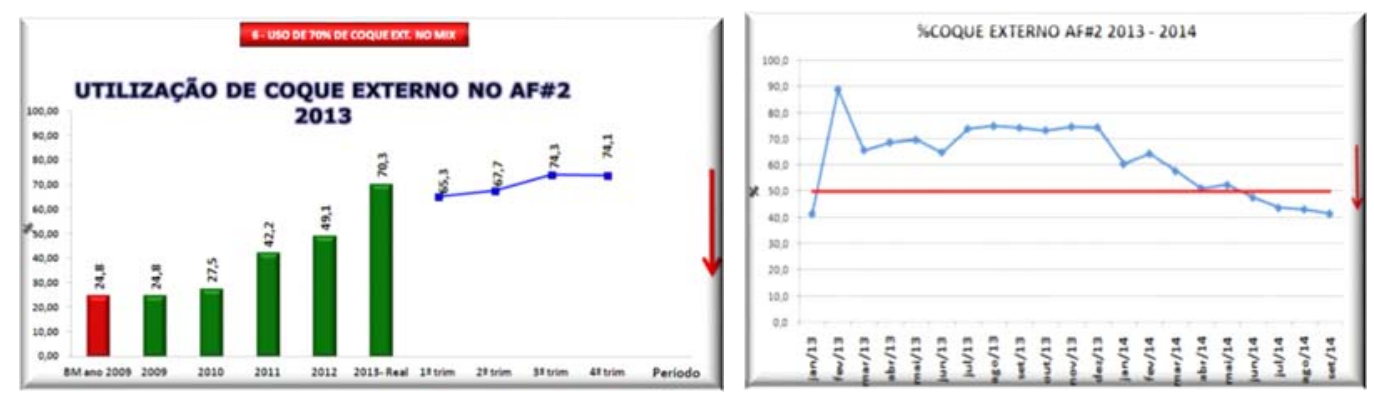

Figura 22 - Percentual de coque externo utilizado no AF\#2 em 2013 e 2014.

\section{RESULTADOS E DISCUSSÃO}

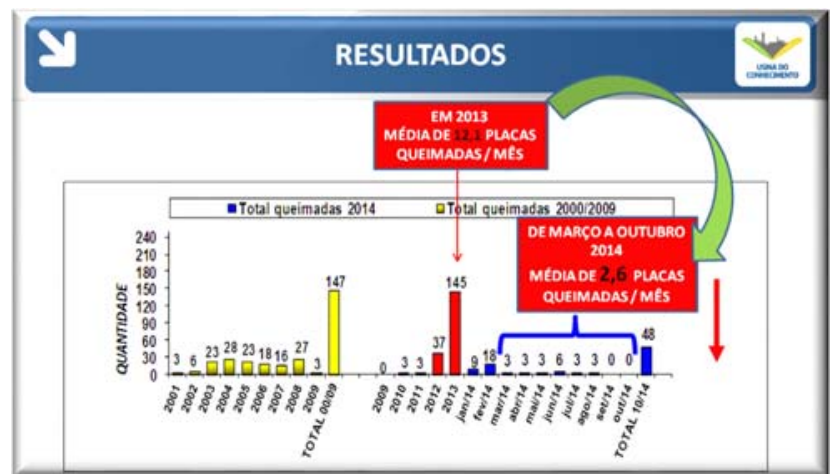

Figura 23 - Comparativo de queima de placas entre 2013 e 2014 


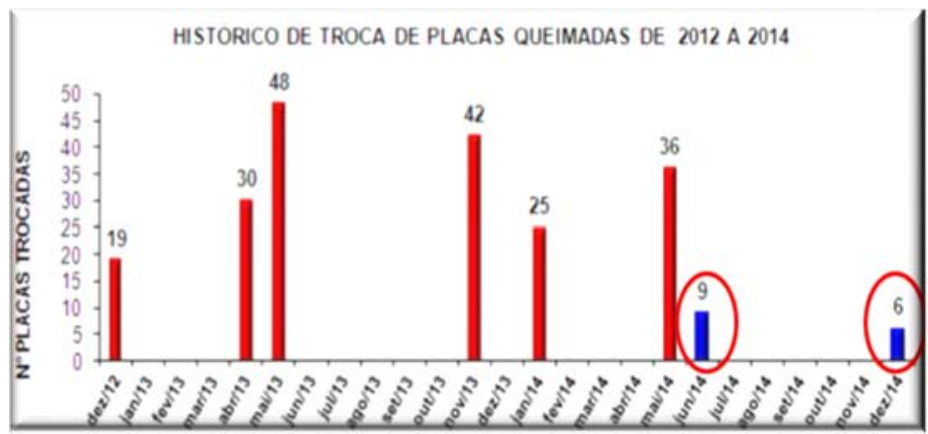

Figura 24 -Número de placas trocadas no AF\#2 em 2013 e 2014

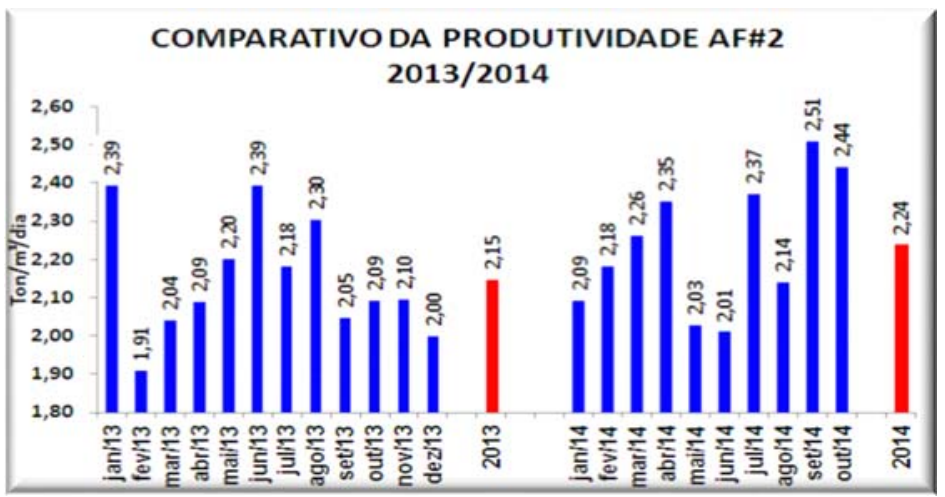

Figura 25 - Comparativo da produtividade no AF\#2 em 2013 e 2014

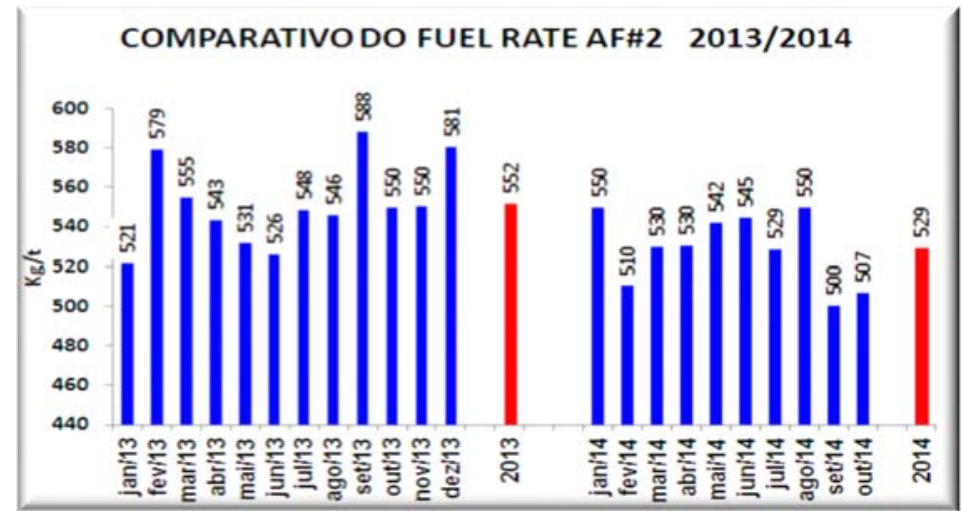

Figura 26 - Comparativo do Fuel Rate no AF\#2 em 2013 e 2014
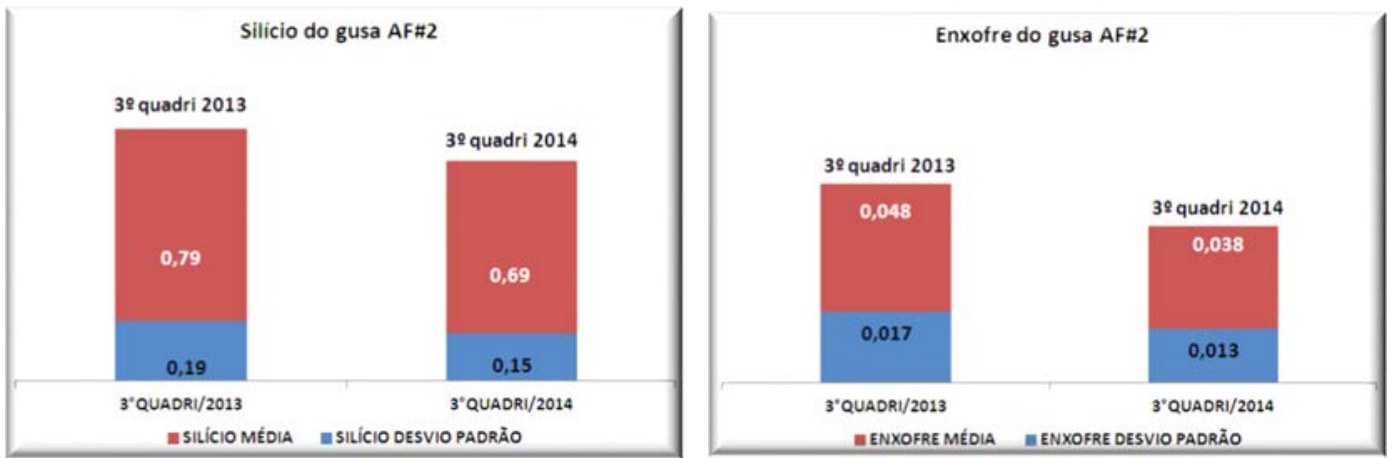

Figura 27 - Comparativo do Sílicio e Enxofre no AF\#2 em 2013 e 2014 


\section{CONCLUSÕES}

- Até o presente momento as ações se mostraram eficazes, contribuindo assim para a redução do número de placas queimadas de 12,1 placas queimadas/mês em 2013 para 2,6 placas queimadas/mês de março a outubro de 2014, representando uma redução na queima de placas de $78,5 \%$;

- Qualidade - Visando prolongar a vida útil da mina de Casa de Pedra e aumentar a produção de minério para exportação foi necessário elevar a participação de minérios de alto teor de ganga na composição do blend, causando elevação dos teores de Sílica no sinter feed e HAF para os altos fornos, o que proporcionou perda do poder dessulfurante e elevação da oferta de Silício para a gusa no AF\#2. Entretanto, com a eficácia das ações e com isso, recuperando a estabilidade da marcha operacional do forno, conseguimos reduzir o desvio padrão e média de silício e enxofre comparando o $3^{\circ}$ quadrimestre de $2013 \mathrm{com}$ o $3^{\circ}$ quadrimestre de 2014 (figura 27);

- Custo e Produtividade - Com a recuperação da estabilidade operacional do AF\#2, através das ações, melhoramos também o desempenho o que representou até outubro de 2014, uma elevação da produtividade de 2,15 em 2013 para 2,24 $\mathrm{t} / \mathrm{m}^{3} /$ dia e uma redução no fuel rate de $552 \mathrm{Kg} / \mathrm{t}$ em 2013 para $529 \mathrm{Kg} / \mathrm{t}$ até outubro de 2014. 